\title{
Effects of glucagon-like peptide-1 receptor agonists on weight loss: systematic review and meta-analyses of randomised controlled trials
}

\author{
@) (1) $\Theta$ OPEN ACCESS
}

\begin{abstract}
Tina Vilsbøll associate professor and chief consultant endocrinologist, Mikkel Christensen specialist registrar, Anders $\mathrm{E}$ Junker registrar, Filip K Knop associate professor and specialist registrar, Lise Lotte Gluud consultant hepatologist
\end{abstract}

Diabetes Research Division, Department of Internal Medicine F, Gentofte Hospital, University of Copenhagen, DK-2900 Hellerup, Denmark

\begin{abstract}
Objective To determine whether treatment with agonists of glucagon-like peptide-1 receptor (GLP-1R) result in weight loss in overweight or obese patients with or without type 2 diabetes mellitus.

Design Systematic review with meta-analyses.

Data sources Electronic searches (Cochrane Library, Medline, Embase, and Web of Science) and manual searches (up to May 2011).

Review methods Randomised controlled trials of adult participants with a body mass index of 25 or higher; with or without type 2 diabetes mellitus; and who received exenatide twice daily, exenatide once weekly, or liraglutide once daily at clinically relevant doses for at least 20 weeks. Control interventions assessed were placebo, oral antidiabetic drugs, or insulin.
\end{abstract}

Data extraction Three authors independently extracted data. We used random effects models for the primary meta-analyses. We also did subgroup, sensitivity, regression, and sequential analyses to evaluate sources of intertrial heterogeneity, bias, and the robustness of results after adjusting for multiple testing and random errors.

Results 25 trials were included in the analysis. GLP-1R agonist groups achieved a greater weight loss than control groups (weighted mean difference $-2.9 \mathrm{~kg}, 95 \%$ confidence interval -3.6 to $-2.2 ; 21$ trials, 6411 participants). We found evidence of intertrial heterogeneity, but no evidence of bias or small study effects in regression analyses. The results were confirmed in sequential analyses. We recorded weight loss in the GLP-1R agonist groups for patients without diabetes $(-3.2 \mathrm{~kg},-4.3$ to -2.1 ; three trials) as well as patients with diabetes $(-2.8 \mathrm{~kg},-3.4$ to -2.3 ; 18 trials). In the overall analysis, GLP-1R agonists had beneficial effects on systolic and diastolic blood pressure, plasma concentrations of cholesterol, and glycaemic control, but did not have a significant effect on plasma concentrations of liver enzymes. GLP-1R agonists were associated with nausea, diarrhoea, and vomiting, but not with hypoglycaemia.
Conclusions The present review provides evidence that treatment with GLP-1R agonists leads to weight loss in overweight or obese patients with or without type 2 diabetes mellitus.

\section{Introduction}

In the United States, more than two thirds of the population is overweight (body mass index 25-29.9) or obese (body mass index $\geq 30$ ). This proportion is smaller in Europe, but continues to increase. ${ }^{1}$ The World Health Organization estimates that 1.5 billion adults worldwide are overweight and 500 million are obese. Almost three million adults die each year as a result of being overweight or obese. An estimated $44 \%$ of the burden for diabetes has been attributed to these weight problems, as well as $23 \%$ and $7-41 \%$ of the burdens for ischaemic heart disease and specific cancers, respectively. ${ }^{2}$

Weight loss is not easily accomplished or maintained. Meta-analyses of clinical trials on non-pharmacological strategies for weight reduction have reported 1-6 kg losses that have been difficult to maintain. ${ }^{3-5}$ Meta-analyses of sibutramine and orlistat trials report average weight reductions of $3 \mathrm{~kg}$ to 5 $\mathrm{kg}$, but some of the included trials had attrition rates of up to $50 \%$ that were possibly due to adverse events, suggesting that the interventions could be less effective in clinical practice. ${ }^{6-8}$ Meta-analyses have found that bariatric surgery reduces long term mortality in obese patients, ${ }^{9}{ }^{10}$ but the safety risks and the costs of this intervention limit the use for large patient populations.

The risk of developing diabetes escalates with the degree of excess body weight, increasing threefold with a body mass index of 25.0 to 29.9 , and 20-fold with an index of 35 and higher compared with a healthy index of 18.5-24.9. ${ }^{11}$ The difficulties encountered in the management of type 2 diabetes are indicated by the low proportion $(<50 \%)$ of patients treated to therapeutic goals. ${ }^{12}{ }^{13}$ Problems in treatment management might be related to shortcomings with the currently available drugs, including 
bodyweight increase (thiazolidinediones, sulphonylureas, and insulin), hypoglycaemia (sulphonylureas, repaglinides, and insulin), and gastrointestinal side effects (metformin and alpha glucosidase inhibitors). ${ }^{14}$

Glucagon-like peptide-1 (GLP-1) is a gut hormone that is secreted from the intestine in response to meal ingestion. GLP-1 based therapy was recently introduced as a new treatment for patients with type 2 diabetes mellitus. Treatment with GLP-1 enhances the endogenous secretion of insulin induced by meal ingestion and inhibits glucagon secretion, thereby improving glucose homoeostasis. Notably, it also suppresses food intake and appetite. Trials of patients with type 2 diabetes suggest that agonists of GLP-1 receptor (GLP-1R) have beneficial effects on metabolic regulation and could lead to weight loss. We did a systematic review and meta-analysis to provide an up to date overview of the beneficial and harmful effects of GLP-1R agonists in patients who are overweight or obese.

\section{Methods}

The present systematic review was based on a written protocol. ${ }^{15}$ The main objective was to assess the effect of GLP-1R agonists versus placebo, no intervention, or other antidiabetic interventions for weight loss in overweight patients with or without type 2 diabetes mellitus. Secondary outcome measures included changes in systolic and diastolic blood pressure, plasma concentrations of liver enzymes (alanine aminotransferase and alkaline phosphatase activity), total cholesterol, and adverse events. For patients with type 2 diabetes, we also assessed markers of glycaemic control: fasting plasma glucose, glycated haemoglobin (percentage of $\mathrm{HbA}_{1 c}$ ), and the proportion of patients achieving a target level of $\mathrm{HbA}_{1 \mathrm{c}}$ less than $7 \%$.

\section{Search strategy for identification of trials}

Eligible trials were identified by electronic and manual searches. We planned to include trials irrespective of publication status or quality of bias control. For the electronic searches, we reviewed the Cochrane Library, Medline, Embase, and Web of Science. We did not make any restrictions regarding the trials' language or year of publication. The last search update was May 2011.

In the Cochrane Library, we used the search strategy for "liraglutide", "glucagon-like peptide-1", or "exenatide". For the remaining databases, the search terms included "glucagon-like peptide-1", "liraglutide", or "exenatide"; and "Randomised Controlled Trial" or "random". These terms were adjusted to fit the requirements specified in each database. We searched trial registries using the search portal of the WHO International Clinical Trial Registry Platform (www.who.int/ ictrp/search/en/).

The reference lists of relevant papers were also reviewed manually. We originally planned to obtain unpublished data from included trials through email correspondence with the first authors of included publications and pharmaceutical companies. Since all trials turned out to be industry funded, we retrieved all additional data by correspondence with pharmaceutical companies.

\section{Review methods and selection criteria}

Eligible trials were listed and the inclusion criteria were assessed independently by all authors. Excluded trials were listed with the reason for exclusion. Three authors (TV, MC, and LLG) extracted data independently. Disagreements were resolved through discussion. Randomised controlled trials were eligible irrespective of their publication status. We included trials of adult patients with or without type 2 diabetes and who had a body mass index of 25 or more. The GLP-1R agonists assessed were exenatide given twice daily, exenatide given once weekly (as a long acting release), and liraglutide given once daily. The control groups were placebo, no intervention, or antidiabetic drugs. If trials included more than one control group, we included data from the most weight neutral intervention (for example, placebo instead of insulin). We also included randomised comparisons between exenatide and liraglutide. To undertake a review that applied to clinical practice, we only included trials with a duration of at least 20 weeks that assessed clinically relevant doses of at least $10 \mu \mathrm{g} /$ day for exenatide (5 $\mu \mathrm{g}$ twice daily), $2 \mathrm{mg} /$ week for exenatide once weekly, and 1.2 $\mathrm{mg}$ /day for liraglutide once daily.

\section{Assessment of risk of bias}

Based on previous evidence, we classed the randomisation methods of selected trials as the primary measure of bias control. ${ }^{16}$ We assessed randomisation methods by how the allocation sequence was generated (classed as adequate if based on a table of random numbers, computer generated random numbers, or similar) and concealed (classed as adequate if based on central randomisation, identically coded drug containers, serially numbered opaque sealed envelopes, or similar).

We also extracted information on the following:

(1) Blinding (whether the trial was described as double blind or single blind, the method of blinding; whether patients, investigators, outcome assessors, or other individuals participating in the trial were blinded; and whether the adequacy of blinding was assessed)

(2) Risk of attrition bias (numbers of and reasons for dropouts and withdrawals, and whether all patients were accounted for in the report and analysis of the trial)

(3) Whether the primary outcome measure was defined and reported

(4) Whether sample size calculations were done

(5) Whether the preset sample size was achieved

(6) For trials terminated prematurely, whether this termination was based on predefined criteria

\section{Statistical analysis}

We did data analyses using Stata version 11 (Stata Corp, TX, USA) and Trial Sequential Analysis 2007 (Copenhagen Trial Unit, Copenhagen, Denmark). We used random effects models for the primary analyses because we expected clinical heterogeneity between trials (owing to different criteria for patient inclusion and different intervention regimens). Results of the meta-analyses were expressed as weighted mean differences for continuous outcomes and relative risks for dichotomous outcomes, both with $95 \%$ confidence intervals, and with $\operatorname{tau}^{2}$ values and $\mathrm{P}$ values as markers of intertrial heterogeneity. For dichotomous outcomes, we calculated the number needed to treat if the outcome measure was significant (that is, the confidence interval did not cross 1). For trials assessing more than one dose of GLP-1R agonist, data from the group allocated to receive the highest dose were included in the primary meta-analysis. We repeated the meta-analysis for the lower doses.

We also repeated the meta-analyses using fixed effects models, to test the robustness of the results after attributing less weight to small trials. We reported the results of the fixed effects 
meta-analyses only if they differed from those of the random effects models. Regression analysis of funnel plot asymmetry allowed us to assess any evidence of publication bias and small study effects (Egger's test). Subgroup analysis examined the intervention effects in trials on different participants (with or without diabetes) and different interventions (that is, exenatide twice daily, exenatide once weekly, or liraglutide once daily).

We did random effects meta-regression to investigate whether body mass index or trial duration could predict the size of the estimated intervention effects. We also used sequential analysis to assess the robustness of the results after adjusting for multiple comparisons (with repeated cumulative meta-analyses). The sequential analysis was done with alpha set to $5 \%$, power to $80 \%$, and a model based heterogeneity correction of $99 \%$. The intervention effects entered in the sequential analysis were selected on the basis of the observed results.

\section{Results}

We identified 694 potentially eligible references using the initial searches (fig $1 \Downarrow$ ). After excluding duplicates and clearly irrelevant references, we retrieved 101 relevant references. Of these references, 76 described subgroup analyses of randomised trials, were non-randomised follow-up studies of trials, or did not assess exenatide or liraglutide at the duration or dose specified in our inclusion criteria. The remaining 25 randomised controlled trials fulfilled our inclusion criteria. ${ }^{171}$ We received additional data that were not described in the published reports on trial methods and outcome measures from 17 of the included trials. ${ }^{17-19} 2224-2630-373940$

All the included trials were published as full paper articles between January 2004 and May 2011 (table $1 \Downarrow$ ). The trials were multicentred (mean number of clinical sites 68) and multinational. Most trials were done in the US and Europe. The duration of individual trials ranged from 20 to 52 weeks. Three trials included patients without diabetes ${ }^{17-19}$ in the remaining trials, all patients were diagnosed with type 2 diabetes.

The patient characteristics at baseline and the diagnostic criteria for type 2 diabetes were very similar across trials. Mean body mass index ranged from 29 to 41, and mean weight from 82 to $111 \mathrm{~kg}$, for both the GLP-1R agonist groups and the control groups. For patients with type 2 diabetes, the mean concentration of fasting plasma glucose at baseline ranged from 8.0 to 11.7 $\mathrm{mmol} / \mathrm{L}$ for GLP-1R agonist groups, and from 8.2 to 11.2 $\mathrm{mmol} / \mathrm{L}$ for control groups. Mean values of $\mathrm{HbA}_{1 \mathrm{c}}$ at baseline ranged from $7.6 \%$ to $10.4 \%$ for GLP-1R agonists and $7.4 \%$ to $10.3 \%$ for controls, respectively.

The included trials assessed exenatide twice daily $(\mathrm{n}=13$ trials), ${ }^{18-21} 242527-2933343638$ liraglutide $(\mathrm{n}=8),{ }^{17} 2632353739-41$ and exenatide once weekly ( $\mathrm{n}=4$; table 1$).^{22} 23031$ Three trials directly compared exenatide twice daily with liraglutide or with exenatide once weekly. ${ }^{23} 2631$. The dose of liraglutide given in most trials was 1.2 or $1.8 \mathrm{mg} /$ day; one trial of obese individuals without diabetes also used doses of 2.4 and $3 \mathrm{mg} / \mathrm{day} .{ }^{17}$ The doses of exenatide used were 10 to $20 \mu \mathrm{g} /$ day or $2 \mathrm{mg} /$ week. The GLP-1R agonists were given as subcutaneous injections once daily for liraglutide, and twice daily and once weekly for exenatide. The control groups received placebo, third generation sulphonylurea compounds, insulin, dipeptidyl peptidase 4 inhibitors, thiazolidinediones, or metformin. In trials of patients with type 2 diabetes, cointerventions given to the intervention and control group included metformin, sulphonylurea compounds, or thiazolidinediones.

\section{Quality of bias control}

Allocation sequence generation and allocation concealment were adequate in all trials. None of the trials found differences in the baseline characteristics of participants between the GLP-1R agonist and control groups. Thirteen trials were double blind, with masking of both patients and investigators. None of the included trials reported the success of blinding. All trials reported clinically relevant outcome measures, provided a clear description of losses to follow-up, accounted for patients with missing data in the analyses, and undertook sample size calculations. None of the trials were terminated prematurely. We found no evidence of reporting bias when comparing published trial protocols with subsequent trial reports.

\section{Body weight}

All trials reported weight loss. We did a random effects meta-analysis including 3395 participants randomly assigned to GLP-1R agonists and 3016 assigned to the control groups, from 21 trials (fig $2 \Downarrow$ ). The control groups in the analysis received placebo, oral antidiabetic drugs, or insulin (table 1). The mean reduction in body weight achieved with the highest dose of GLP-1R agonists ranged from -7.2 to $-0.2 \mathrm{~kg}$. The weighted mean change in body weight was larger for patients in the GLP-1R agonist group than for those in the control group $(-2.9 \mathrm{~kg}, 95 \%$ confidence interval -3.6 to -2.2$)$. We found evidence of intertrial heterogeneity in the analysis $\left(\operatorname{tau}^{2}=2.4\right.$, $\mathrm{P}<0.01$ ). Subgroup analyses showed a greater weight loss after treatment with the highest doses of GLP-1R agonists. We saw a weight reduction in patients without diabetes $(-3.2 \mathrm{~kg},-4.3$ to -2.1$)$ as well as in those with diabetes $(-2.8 \mathrm{~kg},-3.4$ to -2.3$)$. A repeat of the initial meta-analyses with fixed effects models confirmed the primary meta-analysis. The regression analysis did not show any clear evidence of bias or small study effects (Egger's test, $\mathrm{P}>0.1$ for all analyses). We saw no difference in bodyweight changes for patients assigned liraglutide versus exenatide twice daily $(-0.4 \mathrm{~kg}, 95 \%$ confidence interval -1.3 to 0.6 ), or for those assigned exenatide as a long acting release versus exenatide twice daily $(-0.6 \mathrm{~kg},-1.5$ to 0.3$)$. Subgroup analyses showed a weight reduction in trials assessing exenatide twice daily $(-2.8 \mathrm{~kg},-2.9$ to -2.7$)$, exenatide once weekly $(-2.8$ $\mathrm{kg},-5.2$ to -0.3$)$, and liraglutide $(-2.2 \mathrm{~kg},-3.5$ to -0.9$)$. We also saw a weight reduction for trials in which the control group received placebo $(-1.9 \mathrm{~kg},-2.9$ to $-0.9 ; 10$ trials $)$, insulin $(-4.8$ $\mathrm{kg},-5.1$ to -4.5 ; six trials), oral antidiabetic drugs including metformin or sulphonylurea compounds $(-3.0 \mathrm{~kg},-4.9$ to -1.2 ; three trials), and dipeptidyl peptidase 4 inhibitors $(-2.0 \mathrm{~kg},-2.9$ to -1.1 ; two trials). Random effects meta-regression of the primary meta-analysis found that body mass index at baseline and trial duration did not predict the size of the estimated intervention or explain intertrial heterogeneity $(\mathrm{P}=0.293$ and $\mathrm{P}=0.284$, respectively).

We did the sequential analysis based on the results of the primary meta-analysis, including the highest dose of GLP-1R agonists assessed compared with controls. The analysis showed that the cumulative $Z$ curve crossed the monitoring boundary after the seventh trial, which suggested that we had sufficient evidence (that is, the optimal information size was reached) to confirm the intervention effect after adjusting for multiple testing and random error.

\section{Blood pressure, cholesterol, and liver enzymes}

Random effects meta-analyses found that the GLP-1R agonists reduced systolic blood pressure (fig $3 \Downarrow$ ), diastolic blood pressure 
(fig $4 \Downarrow$ ), and total cholesterol concentrations (fig $5 \Downarrow$ ). We found no evidence of bias for the analysis of systolic or diastolic blood pressure (Egger's test, $\mathrm{P}=0.500$ and $\mathrm{P}=0.107$, respectively) or cholesterol $(\mathrm{P}=0.081)$.

We retrieved data for liver enzymes from 17 trials. However, since these data were reported inconsistently, we were only able to include data from 12 of these trials (fig $6 \Downarrow$ ). The overall difference in concentrations of alanine aminotransferase was significant in the fixed effects meta-analysis, but not in the random effects analysis $(-1.0 \mathrm{U} / \mathrm{L}, 95 \%$ confidence interval -2.5 to 0.6$)$. In subgroup analyses, alanine aminotransferase concentrations decreased after treatment with liraglutide $(-2.2$ $\mathrm{U} / \mathrm{L},-3.6$ to -0.9$)$ but not with exenatide $(0.7 \mathrm{U} / \mathrm{L},-1.1$ to 2.4$)$. GLP-1R agonists did not have a clear effect on alkaline phosphatase concentrations after treatment in the overall analysis (1.1 U/L, -0.6 to 2.8 ) or in separate analyses of liraglutide or exenatide. We also did not see any evidence of small study effects in regression analyses (Egger's test; alanine aminotransferase, $\mathrm{P}=0.371$; alkaline phosphatase, $\mathrm{P}=0.123$ ).

\section{Glycaemic control (patients with type 2 diabetes)}

In patients with type 2 diabetes, the highest doses of GLP-1R agonists reduced $\mathrm{HbA}_{1 \mathrm{c}}$ percentage compared with placebo, oral antidiabetic drugs, or insulin (fig $7 \Downarrow$; Egger's test, $P=0.764$ ). In the random effects analysis, we saw no clear difference in the change in mean concentration of fasting blood glucose between the highest doses of GLP-1R agonists and controls $(-0.51$ $\mathrm{mmol} / \mathrm{L}, 95 \%$ confidence interval -1.09 to $0.07 ; \mathrm{tau}^{2}=1.06 ; \chi^{2}$ test, $\mathrm{P}<0.01$; Egger's test, $\mathrm{P}=0.487$ ). When using a fixed effects model, we found that GLP-1R agonists were associated with a greater reduction in concentrations of fasting glucose than controls $(-1.32 \mathrm{mmol} / \mathrm{L},-1.35$ to -1.29$)$.

The proportion of participants who achieved the haemoglobin target $\left(\mathrm{HbA}_{1 \mathrm{c}}<7 \%\right)$ was higher in the GLP-1R agonists group than in controls (relative risk $1.98,95 \%$ confidence interval 1.46 to $2.70 ; \mathrm{tau}^{2}=0.28 ; \chi^{2}$ test, $\mathrm{P}=0.10$ ). The corresponding number needed to treat was six patients (four to 10 patients). Egger's test found evidence of small study effects $(\mathrm{P}=0.001)$. Repeating the primary analysis with a fixed effects model confirmed the overall results (relative risk 1.75, 1.59 to 1.92). We found similar results for trials using a lower dose of GLP-1R agonist (that is, liraglutide $1.2 \mathrm{mg} /$ day and exenatide $10 \mu \mathrm{g} /$ day).

When comparing the highest dose with the lowest dose of GLP-1R agonists assessed in the individual trials, random effects meta-analysis showed that the highest doses were associated with a greater reduction in mean $\mathrm{HbA}_{1 \mathrm{c}}(-0.10 \%,-0.17 \%$ to $-0.02 \%$ ) and increased the proportion of patients who achieved the target $\mathrm{HbA}_{1 \mathrm{c}}$ (relative risk 1.14, 1.03 to 1.27). We saw no difference between the two highest and lowest doses when analysing the mean reduction in fasting blood glucose (weighted mean difference $-0.14 \mathrm{mmol} / \mathrm{L},-0.31$ to 0.03 ). We saw a similar result after repeating the meta-analyses with fixed effects models.

\section{Adverse events}

The trials registered several adverse events (table $2 \Downarrow$ ). Overall, GLP-1R agonists did not increase the number of patients who withdrew or dropped out. The most frequent adverse events were hypoglycaemia and gastrointestinal adverse events (nausea, diarrhoea, and vomiting). Adverse events became more frequent with increasing doses. We found few serious adverse events (such as major episodes of hypoglycaemia).

\section{Discussion}

The present meta-analyses include data from randomised controlled trials assessing clinically relevant doses of GLP-1R agonists given for at least 20 weeks. The results indicate that treatment with GLP-1R agonists help reduce body weight in patients who are overweight or obese. Three of the included trials assessed the effect of GLP-1R agonists on patients without type 2 diabetes and 22 assessed patients with type 2 diabetes. GLP-1R agonists also had beneficial effects on systolic and diastolic blood pressure. In subgroup and sensitivity analyses, the liver enzyme activity was lower in the GLP-1R agonist groups than in the control groups. However, the overall effect of GLP-1R agonists on liver enzymes was not clear. For patients with type 2 diabetes, GLP-1R agonists improved glycaemic control (as assessed by $\mathrm{HbA}_{1 \mathrm{c}}$ percentage and fasting plasma glucose) and increased the proportion of patients who achieved the target haemoglobin.

GLP-1R agonists were associated with several adverse events. Gastrointestinal side effects (such as nausea, vomiting, and diarrhoea) were common, but did not seem to affect the number of losses to follow-up. These findings concur with recent evidence showing that the overall patient satisfaction with GLP-1R agonist treatment is relatively high. ${ }^{42}$

In patients with type 2 diabetes, improved glycaemic control is often associated with increased body weight. ${ }^{43}$ We found that participants without diabetes achieved greater reductions in body weight than those with diabetes. Our results suggest that treatment with GLP-1R agonists are an effective intervention for participants who are overweight, irrespective of whether they have diabetes. GLP-1R agonists could be especially relevant for patients with hypertension, raised cholesterol, or other conditions in the metabolic syndrome. However, additional trials investigating the effect of comorbidities (such as cardiovascular diseases) are still warranted.

In developed countries, obesity increases mortality and morbidity as well as the frequency of type 2 diabetes, hypertension, and non-alcoholic fatty liver disease. Obesity, particularly with an excess of visceral or ectopic fat, is an independent risk factor for heart disease and several studies suggest that obesity has detrimental effects on complications to infectious diseases, ${ }^{44}$ quality of life and depression, ${ }^{45}$ and cancer related mortality. ${ }^{46}$ These diseases have an important impact on the individuals affected, and the management of complications to obesity puts an increasing strain on the healthcare systems. A recent German study found that the cost associated with obesity is apparent even from childhood. ${ }^{47}$ Since nearly 50 million children under the age of 5 years are overweight, ${ }^{2}$ we are facing a huge medical, as well as financial, challenge worldwide. Accordingly, identification of effective interventions for weight reductions is crucial. The costs with interventions that lead to lasting weight reduction should be considered in relation to those with the treatment of complications to obesity.

In 2005, the US Food and Drug Administration approved the first long acting stable GLP-1R agonist. Two products are currently available on the market: exenatide (Byetta; Eli Lilly) and liraglutide (Victoza; Novo Nordisk). Both drugs are injectable medications that can be used in combination with oral antidiabetic drugs such as metformin, thiazolidinediones, or sulphonylurea compounds. The treatments are approved for patients with type 2 diabetes who have not achieved adequate glycaemic control after treatment with conventional antidiabetic interventions. Exenatide treatment is initiated at a $5 \mu \mathrm{g}$ dose given twice daily for at least one month to improve tolerability. 
The dose can subsequently be increased to a maximum of 10 $\mu \mathrm{g}$ twice daily to improve glycaemic control. ${ }^{48}$

In October 2011, exenatide as a once weekly injection (Bydureon; Eli Lilly) reached the European market for the treatment of type 2 diabetes, with similar indications as for exenatide twice daily and liraglutide. The starting dose of exenatide once weekly is $2 \mathrm{mg} /$ week with no need for titration. The starting dose of liraglutide is $0.6 \mathrm{mg} / \mathrm{day}$; after one week, the daily dose is increased to $1.2 \mathrm{mg}$, based on the clinical response and side effects, and can be increased further to 1.8 $\mathrm{mg} /$ day the following week, depending on efficacy and adverse events. ${ }^{49}$ The trials included in the present review followed these intervention regimens, although one trial also assessed liraglutide doses of 2.4-3.0 mg/day in obese individuals without diabetes. ${ }^{17}$ These doses seemed to further increase not only the achieved bodyweight loss, but also the number of gastrointestinal adverse events. ${ }^{17}$ None of the remaining trials assessed equally high doses.

Patients with obesity and type 2 diabetes have an increased risk of developing non-alcoholic fatty liver disease.$^{50}$ This disease could have a benign course, although it progresses to non-alcoholic steatohepatitis in about $20-30 \%$ of patients. Although histological markers remain the best method for assessing the severity of fatty liver disease, liver enzymes are associated with the disease activity in the early stages of non-alcoholic steatohepatitis. We found no clear effect of GLP-1R agonists on liver enzyme activity. However, since we did not analyse histological changes, additional trials are needed to investigate the effects of GLP-1R agonists in participants with overweight and non-alcoholic fatty liver disease.

\section{Strengths and limitations of the findings}

Unlike previous reviews, we were able to gather data for outcomes that were not described in the published reports. ${ }^{17} 192224-2630-373940$ Outcome measures are less likely to be described in published reports if the result is not significant. Therefore, the retrieval of unpublished outcome data could reduce the risk of reporting bias (that is, selective reporting of outcomes with a positive result). The present review also differed from previous reviews by the inclusion of patients without type 2 diabetes mellitus. Although the non-specific inclusion criteria increased intertrial heterogeneity, they also improved the external validity of our findings. Furthermore, to achieve and maintain clinically relevant weight loss, we only included trials that followed participants for a sufficient period (20 weeks or more).

Inadequate randomisation and attrition bias could lead to overestimated benefits of an intervention. None of the included trials had deficiencies in the reported randomisation methods and all accounted for the intention to treat population in their results and analyses. These aspects support the internal validity of our findings. Since we only included trials that used clinically relevant doses given for clinically relevant treatment periods, the results can be extrapolated to clinical practice. Accordingly, the present review can help evidence based practitioners determine the size of the treatment benefit.

All the included trials received industry funding. Previous evidence and clinical examples have described that financial interests could lead to bias in intervention comparisons. ${ }^{16}$ On the other hand, funding could be associated with adequate control of bias. ${ }^{51}$ Furthermore, in a large cohort of randomised trials, industry funding was associated with more positive author conclusions, but not with the quantitative results of the trials. ${ }^{52}$ Since we did not identify trials without funding, we were unable to make subgroup analyses to explore the potential effect of competing interests. We did, however, undertake rigorous assessments of the quality of included trials. None of our analyses showed any evidence of selection, assessment, attrition, or outcome reporting bias. These analyses support the validity of our results.

\section{Conclusions and clinical implications}

Participants who are overweight are likely to develop type 2 diabetes, hypertension, hypercholesterolaemia, liver disease, and eventually cardiovascular disease. Accordingly, these participants have a considerably elevated risk of morbidity and mortality. Traditional treatments for obesity are, unfortunately, often short lived and consequently not especially effective.

Current treatments for patients with type 2 diabetes are associated with shortcomings (weight gain, hypoglycaemia, and other side effects) that limit the number of patients reaching acceptable therapeutic goals. The present meta-analysis provides convincing evidence that GLP-1R agonists, when given to obese patients with or without diabetes, results in clinically relevant beneficial effects on body weight. Additional beneficial effects on blood pressure and total cholesterol might also be achieved. The intervention should be considered in patients with diabetes who are obese or overweight. Further studies are needed to elucidate the effects of GLP-1R agonists in the treatment of obese patients without diabetes.

We thank Novo Nordisk and Eli Lilly/Amylin who provided additional data from the trials funded by the two pharmaceutical companies; Jørn Wetterslev for his help with the sequential analyses; and Anne-Marie Demuth Jørgensen for technical assistance.

Contributors: TV, FKK, and LLG designed the study. All authors participated in the literature searches and extracted data. TV coordinated the collection of unpublished data and is the study guarantor. LLG did the data analyses. All authors contributed to the interpretation of the data, revised the paper for important intellectual content, and approved the final version.

Funding: The present work has not received funding.

Competing interests: All authors have completed the Unified Competing Interest form at www.icmje.org/coi_disclosure.pdf (available on request from the corresponding author) and declare: no received support from any organisation for the submitted work; no relationships with any organisations that might have an interest in the submitted work in the previous 3 years; and no other relationships or activities that could appear to have influenced the submitted work.

Ethical approval: Not required.

Data sharing: No additional data available.

1 Finucane MM, Stevens GA, Cowan MJ, Danaei G, Lin JK, Paciorek CJ, et al. National, regional, and global trends in body-mass index since 1980: systematic analysis of health examination surveys and epidemiological studies with 960 country-years and $9 \cdot 1$ million participants. Lancet 2011;377:557-67.

2 World Health Organization. Obesity and overweight. 2011. www.who.int/mediacentre/ factsheets/fs311/en/.

3 Norris SL, Zhang X, Avenell A, Gregg E, Brown TJ, Schmid CH, et al. Long-term non-pharmacologic weight loss interventions for adults with type 2 diabetes. Cochrane Database Syst Rev 2005;2:CD004095.

4 Franz MJ, VanWormer JJ, Crain AL, Boucher JL, Histon T, Caplan W, et al. Weight-loss outcomes: a systematic review and meta-analysis of weight-loss clinical trials with a minimum 1-year follow-up. J Am Diet Assoc 2007;107:1755-67.

5 Gourlan MJ, Trouilloud DO, Sarrazin PG. Interventions promoting physical activity among obese populations: a meta-analysis considering global effect, long-term maintenance, physical activity indicators and dose characteristics. Obes Rev 2011;12:e633-45.

6 Padwal R, Li SK, Lau DCW. Long-term pharmacotherapy for obesity and overweight. Cochrane Database Syst Rev 2003;4:CD004094.

7 Rucker D, Padwal R, Li SK, Curioni C, Lau DCW. Long term pharmacotherapy for obesity and overweight: updated meta-analysis. BMJ 2007;335:1194-9.

8 Li M, Cheung BMY. Pharmacotherapy for obesity. Br J Clin Pharmacol 2009;68:804-10.

9 Padwal R, Klarenbach S, Wiebe N, Birch D, Karmali S, Manns B, et al. Bariatric surgery: a systematic review and network meta-analysis of randomized trials. Obes Rev 2011;12:602-21. 


\section{What is already known on this topic}

Improved glycaemic control is associated with increased body weight

Agonists to the glucagon-like peptide-1 receptor (GLP-1R) enhance glucose homoeostasis and suppress food intake and appetite

\section{What this study adds}

Treatment with clinically relevant doses of GLP-1R agonists for at least 20 weeks leads to weight loss in obese or overweight patients with or without type 2 diabetes mellitus in spite of an improved metabolic regulation

The effect of GLP-1R agonists could be more pronounced in patients without diabetes

GLP-1R agonists also reduce systolic and diastolic blood pressure and total cholesterol

10 Pontiroli AE, Morabito A. Long-term prevention of mortality in morbid obesity through bariatric surgery. A systematic review and meta-analysis of trials performed with gastric banding and gastric bypass. Ann Surg 2011;253:484-7.

11 Field AE, Coakley EH, Must A, Spadano JL, Laird N, Dietz WH, et al. Impact of overweight on the risk of developing common chronic diseases during a 10-year period. Arch Intern Med 2001;161:1581-6.

12 Cheung BMY, Ong KL, Cherny SS, Sham P-C, Tso AWK, Lam KSL. Diabetes prevalence and therapeutic target achievement in the United States, 1999 to 2006. Am J Med 2009;122:443-53

13 American Diabetes Association. Standards of medical care in diabetes-2008. Diabetes Care 2008;31(suppl 1):S12-54

14 Bolen S, Feldman L, Vassy J, Wilson L, Yeh H-C, Marinopoulos S, et al. Systematic review: comparative effectiveness and safety of oral medications for type 2 diabetes mellitus. Ann Intern Med 2007:147:386-99.

15 The Cochrane Collaboration. Cochrane handbook for systematic reviews of interventions. 2011. www.cochrane.org/training/cochrane-handbook.

16 Wood L, Egger M, Gluud LL, Schulz KF, Jüni P, Altman DG, et al. Empirical evidence of bias in treatment effect estimates in controlled trials with different interventions and outcomes: meta-epidemiological study. BMJ 2008;336:601-5.

17 Astrup A, Rössner S, Van Gaal L, Rissanen A, Niskanen L, Al Hakim M, et al. Effects of liraglutide in the treatment of obesity: a randomised, double-blind, placebo-controlled study. Lancet 2009;374:1606-16.

18 Elkind-Hirsch K, Marrioneaux O, Bhushan M, Vernor D, Bhushan R. Comparison of single and combined treatment with exenatide and metformin on menstrual cyclicity in overweight women with polycystic ovary syndrome. J Clin Endocrinol Metab 2008;93:2670-8.

19 Rosenstock J, Klaff LJ, Schwartz S, Northrup J, Holcombe JH, Wilhelm K, et al. Effects of exenatide and lifestyle modification on body weight and glucose tolerance in obese subjects with and without pre-diabetes. Diabetes Care 2010;33:1173-5.

20 Apovian CM, Bergenstal RM, Cuddihy RM, Qu Y, Lenox S, Lewis MS, et al. Effects of exenatide combined with lifestyle modification in patients with type 2 diabetes. Am J Med 2010;123:468,e9-17.

21 Bergenstal R, Lewin A, Bailey T, Chang D, Gylvin T, Roberts V. Efficacy and safety of biphasic insulin aspart 70/30 versus exenatide in subjects with type 2 diabetes failing to achieve glycemic control with metformin and a sulfonylurea. Curr Med Res Opin 2009;25:65-75

22 Bergenstal RM, Wysham C, Macconell L, Malloy J, Walsh B, Yan P, et al. Efficacy and safety of exenatide once weekly versus sitagliptin or pioglitazone as an adjunct to metformin for treatment of type 2 diabetes (DURATION-2): a randomised trial. Lancet 2010;376:431-9.

23 Blevins T, Pullman J, Malloy J, Yan P, Taylor K, Schulteis C, et al. DURATION-5: exenatide once weekly resulted in greater improvements in glycemic control compared with exenatide twice daily in patients with type 2 diabetes. J Clin Endocrinol Metab 2011;96:1301-10.

24 Bunck MC, Diamant M, Cornér A, Eliasson B, Malloy JL, Shaginian RM, et al. One-year treatment with exenatide improves beta-cell function, compared with insulin glargine, in metformin-treated type 2 diabetic patients: a randomized, controlled trial. Diabetes Care 2009;32:762-8

25 Buse JB, Henry RR, Han J, Kim DD, Fineman MS, Baron AD. Effects of exenatide (exendin-4) on glycemic control over 30 weeks in sulfonylurea-treated patients with type 2 diabetes. Diabetes Care 2004;27:2628-35.

26 Buse JB, Rosenstock J, Sesti G, Schmidt WE, Montanya E, Brett JH, et al. Liraglutide once a day versus exenatide twice a day for type 2 diabetes: a 26 -week randomised, parallel-group, multinational, open-label trial (LEAD-6). Lancet 2009;374:39-47.

27 Davis SN, Johns D, Maggs D, Xu H, Northrup JH, Brodows RG. Exploring the substitution of exenatide for insulin in patients with type 2 diabetes treated with insulin in combination with oral antidiabetes agents. Diabetes Care 2007;30:2767-72.

28 DeFronzo RA, Triplitt C, Qu Y, Lewis MS, Maggs D, Glass LC. Effects of exenatide plus rosiglitazone on beta-cell function and insulin sensitivity in subjects with type 2 diabetes on metformin. Diabetes Care 2010;33:951-7.

29 Derosa G, Maffioli P, Salvadeo SAT, Ferrari I, Ragonesi PD, Querci F, et al. Exenatide versus glibenclamide in patients with diabetes. Diabetes Technol Ther 2010;12:233-40.

30 Diamant M, Van Gaal L, Stranks S, Northrup J, Cao D, Taylor K, et al. Once weekly exenatide compared with insulin glargine titrated to target in patients with type 2 diabetes (DURATION-3): an open-label randomised trial. Lancet 2010;375:2234-43.

31 Drucker DJ, Buse JB, Taylor K, Kendall DM, Trautmann M, Zhuang D, et al. Exenatide once weekly versus twice daily for the treatment of type 2 diabetes: a randomised, open-label, non-inferiority study. Lancet 2008;372:1240-50

32 Garber A, Henry R, Ratner R, Garcia-Hernandez PA, Rodriguez-Pattzi H, Olvera-Alvarez I, et al. Liraglutide versus glimepiride monotherapy for type 2 diabetes (LEAD-3 Mono): a randomised, 52-week, phase III, double-blind, parallel-treatment trial. Lancet 2009;373:473-81

33 Heine RJ, Van Gaal LF, Johns D, Mihm MJ, Widel MH, Brodows RG. Exenatide versus insulin glargine in patients with suboptimally controlled type 2 diabetes: a randomized trial. Ann Intern Med 2005;143:559-69.
34 Kendall DM, Riddle MC, Rosenstock J, Zhuang D, Kim DD, Fineman MS, et al. Effects of exenatide (exendin-4) on glycemic control over 30 weeks in patients with type 2 diabetes treated with metformin and a sulfonylurea. Diabetes Care 2005;28:1083-91.

35 Marre M, Shaw J, Brändle M, Bebakar WMW, Kamaruddin NA, Strand J, et al. Liraglutide, a once-daily human GLP-1 analogue, added to a sulphonylurea over 26 weeks produces greater improvements in glycaemic and weight control compared with adding rosiglitazone or placebo in subjects with type 2 diabetes (LEAD-1 SU). Diabet Med 2009:26-268-78.

36 Moretto TJ, Milton DR, Ridge TD, Macconell LA, Okerson T, Wolka AM, et al. Efficacy and tolerability of exenatide monotherapy over 24 weeks in antidiabetic drug-naive patients with type 2 diabetes: a randomized, double-blind, placebo-controlled, parallel-group study. Clin Ther 2008;30:1448-60

37 Nauck M, Frid A, Hermansen K, Shah NS, Tankova T, Mitha IH, et al. Efficacy and safety comparison of liraglutide, glimepiride, and placebo, all in combination with metformin, in type 2 diabetes: the LEAD (liraglutide effect and action in diabetes)-2 study. Diabetes Care 2009;32:84-90.

38 Nauck MA, Duran S, Kim D, Johns D, Northrup J, Festa A, et al. A comparison of twice-daily exenatide and biphasic insulin aspart in patients with type 2 diabetes who were suboptimally controlled with sulfonylurea and metformin: a non-inferiority study. Diabetologia 2007;50:259-67.

39 Pratley RE, Nauck M, Bailey T, Montanya E, Cuddihy R, Filetti S, et al. Liraglutide versus sitagliptin for patients with type 2 diabetes who did not have adequate glycaemic control with metformin: a 26-week, randomised, parallel-group, open-label trial. Lancet 2010;375:1447-56

40 Russell-Jones D, Vaag A, Schmitz O, Sethi BK, Lalic N, Antic S, et al. Liraglutide vs insulin glargine and placebo in combination with metformin and sulfonylurea therapy in type 2 diabetes mellitus (LEAD-5 met+SU): a randomised controlled trial. Diabetologia 2009:52:2046-55

41 Zinman B, Gerich J, Buse JB, Lewin A, Schwartz S, Raskin P, et al. Efficacy and safety of the human glucagon-like peptide-1 analog liraglutide in combination with metformin and thiazolidinedione in patients with type 2 diabetes (LEAD-4 Met+TZD). Diabetes Care 2009;32:1224-30

42 Davies M, Pratley R, Hammer M, Thomsen AB, Cuddihy R. Liraglutide improves treatmen satisfaction in people with type 2 diabetes compared with sitagliptin, each as an add on to metformin. Diabet Med 2011;28:333-7.

43 UK Prospective Diabetes Study (UKPDS) Group. Intensive blood-glucose control with sulphonylureas or insulin compared with conventional treatment and risk of complications in patients with type 2 diabetes (UKPDS 33). Lancet 1998;352:837-53.

44 Fezeu L, Julia C, Henegar A, Bitu J, Hu FB, Grobbee DE, et al. Obesity is associated with higher risk of intensive care unit admission and death in influenza $\mathrm{A}$ (H1N1) patients: a systematic review and meta-analysis. Obes Rev 2011;12:653-9

45 Fabricatore AN, Wadden TA, Higginbotham AJ, Faulconbridge LF, Nguyen AM, Heymsfield $\mathrm{SB}$, et al. Intentional weight loss and changes in symptoms of depression: a systematic review and meta-analysis. Int J Obes (Lond) 2011; published online 22 February.

46 Cao Y, Ma J. Body mass index, prostate cancer-specific mortality, and biochemical recurrence: a systematic review and meta-analysis. Cancer Prev Res (Phila) 2011:4:486-501.

47 Breitfelder A, Wenig CM, Wolfenstetter SB, Rzehak P, Menn P, John J, et al. Relative weight-related costs of healthcare use by children-results from the two German birth cohorts, GINI-plus and LISA-plus. Econ Hum Biol 2011;9:302-15.

48 European Medicines Agency. Eli Lilly \& Co, summary of product characteristics. Byetta TM, 2011.

49 European Medicines Agency. Novo Nordisk, summary of product characteristics. Victoza TM, 2010.

50 Ismail MH. Nonalcoholic fatty liver disease and type 2 diabetes mellitus: the hidden epidemic. Am J Med Sci 2011;341:485-92.

51 Kjaergard LL, Gluud C. Funding, disease area, and internal validity of hepatobiliary randomized clinical trials. Am J Gastroenterol 2002:97:2708-13.

52 Als-Nielsen B, Chen W, Gluud C, Kjaergard LL. Association of funding and conclusions in randomized drug trials: a reflection of treatment effect or adverse events? JAMA 2003;290:921-8.

\section{Accepted: 3 October 2011}

\section{Cite this as: BMJ 2012;344:d7771}

This is an open-access article distributed under the terms of the Creative Commons Attribution Non-commercial License, which permits use, distribution, and reproduction in any medium, provided the original work is properly cited, the use is non commercial and is otherwise in compliance with the license. See: http://creativecommons.org/licenses/by$\mathrm{nc} / 2.0 /$ and http://creativecommons.org/licenses/by-nc/2.0/legalcode. 


\section{Tables}

\section{Table 1 | Characteristics of included trials}

\begin{tabular}{|c|c|c|c|c|c|}
\hline Trial & Year & Patients (n) & Intervention & Duration (weeks) & Main inclusion criteria \\
\hline Astrup $^{17}$ & 2009 & 371 & Liraglutide; orlistate; placebo & 24 & Obesity \\
\hline Elkind-Hirsch ${ }^{18}$ & 2008 & 60 & Exenatide; metformin; exenatide and metformin & 24 & Obesity \\
\hline Rosenstock $^{19}$ & 2010 & 163 & Exenatide; placebo & 24 & Obesity \\
\hline Apovian $^{20}$ & 2010 & 194 & Exenatide; placebo & 24 & Type 2 diabetes \\
\hline Bergenstal $^{21}$ & 2009 & 372 & Exenatide; insulin & 24 & Type 2 diabetes \\
\hline Bergenstal $^{22}$ & 2010 & 491 & Exenatide; sitagliptin; pioglitazone & 26 & Type 2 diabetes \\
\hline Blevins $^{23}$ & 2011 & 252 & Exenatide once weekly; exenatide twice daily & 24 & Type 2 diabetes \\
\hline Bunck $^{24}$ & 2009 & 69 & Exenatide; insulin glargine & 52 & Type 2 diabetes \\
\hline Buse $^{25}$ & 2004 & 377 & Exenatide; placebo & 30 & Type 2 diabetes \\
\hline Buse $^{26}$ & 2009 & 464 & Liraglutide; exenatide & 26 & Type 2 diabetes \\
\hline Davis $^{27}$ & 2007 & 49 & Exenatide; insulin & 20 & Type 2 diabetes \\
\hline DeFronzo $^{28}$ & 2010 & 137 & Exenatide; rosiglitazone & 20 & Type 2 diabetes \\
\hline Derosa $^{29}$ & 2010 & 128 & Exenatide; glibenclamide & 52 & Type 2 diabetes \\
\hline Diamant $^{30}$ & 2010 & 456 & Exenatide; insulin glargine & 26 & Type 2 diabetes \\
\hline Drucker $^{31}$ & 2008 & 303 & Exenatide once weekly; exenatide twice daily & 30 & Type 2 diabetes \\
\hline Garber $^{32}$ & 2009 & 746 & Liraglutide; glimepiride & 52 & Type 2 diabetes \\
\hline Heine $^{33}$ & 2005 & 551 & Exenatide; insulin glargine & 26 & Type 2 diabetes \\
\hline Kendall $^{34}$ & 2005 & 733 & Exenatide; placebo & 30 & Type 2 diabetes \\
\hline Marre $^{35}$ & 2009 & 1041 & Liraglutide; rosiglitazone; placebo & 26 & Type 2 diabetes \\
\hline Moretto $^{36}$ & 2008 & 232 & Exenatide; placebo & 24 & Type 2 diabetes \\
\hline Nauck $^{37}$ & 2007 & 501 & Exenatide; insulin & 53 & Type 2 diabetes \\
\hline Nauck $^{38}$ & 2009 & 1091 & Liraglutide; glimepiride; placebo & 26 & Type 2 diabetes \\
\hline Pratley $^{39}$ & 2010 & 665 & Liraglutide; sitagliptin & 26 & Type 2 diabetes \\
\hline Russell-Jones ${ }^{40}$ & 2009 & 581 & Liraglutide; insulin glargine; placebo & 26 & Type 2 diabetes \\
\hline Zinman $^{41}$ & 2009 & 533 & Liraglutide; placebo, metformin, and rosiglitazone & 26 & Type 2 diabetes \\
\hline
\end{tabular}


Table 2| Adverse events in randomised controlled trials, by specific comparisons

\begin{tabular}{|c|c|c|c|}
\hline \multirow[t]{2}{*}{ Adverse event } & \multicolumn{2}{|c|}{ Comparator group $(\mathrm{n} / \mathrm{N})$} & \multirow[t]{2}{*}{ Relative risk $(95 \% \mathrm{Cl})$} \\
\hline & 1 & 2 & \\
\hline \multicolumn{4}{|c|}{ High dose GLP-1R agonists $v$ control interventions ${ }^{*} \dagger$} \\
\hline Withdrawal & $578 / 3142$ & $616 / 2768$ & 0.85 (0.71 to 1.0$)$ \\
\hline Hypoglycaemia (major episodes) & $341(10) / 2281$ & $342(16) / 2036$ & $0.98(0.60$ to 1.59$)$ \\
\hline Nausea & 935/2845 & $219 / 2556$ & 4.33 (3.16 to 5.94$)$ \\
\hline Vomiting & $277 / 2494$ & 100/2245 & 2.91 (1.93 to 4.39$)$ \\
\hline Diarrhoea & $305 / 2411$ & $127 / 2157$ & 2.19 (1.79 to 2.68$)$ \\
\hline \multicolumn{4}{|c|}{ High dose GLP-1R agonists $v$ low dose GLP-1R agonists†‡ } \\
\hline Withdrawal & $346 / 1893$ & 423/1658 & $0.71(0.60$ to 0.85$)$ \\
\hline Hypoglycaemia (major episodes) & $168(0) / 1335$ & $119(0) / 1214$ & $1.57(0.65$ to 3.81$)$ \\
\hline Nausea & $469 / 1425$ & $134 / 1312$ & 3.96 (2.67 to 5.87$)$ \\
\hline Vomiting & $150 / 1425$ & 69/1312 & 2.67 (1.47 to 4.84$)$ \\
\hline Diarrhoea & $171 / 1247$ & $65 / 1135$ & 2.35 (1.78 to 3.10$)$ \\
\hline \multicolumn{4}{|c|}{ Low dose GLP-1R agonists $v$ control interventions ${ }^{*} \ddagger$} \\
\hline Withdrawal & $332 / 1665$ & $392 / 1426$ & $0.71(0.52$ to 0.97$)$ \\
\hline Hypoglycaemia (major episodes) & $134(1) / 1342$ & $119(0) / 1214$ & $1.37(0.75$ to 2.52$)$ \\
\hline Nausea & $399 / 1665$ & $136 / 1426$ & 3.21 (2.18 to 4.72$)$ \\
\hline Vomiting & $131 / 1437$ & 69/1312 & $2.32(1.03$ to 5.21$)$ \\
\hline Diarrhoea & $121 / 1259$ & $65 / 1135$ & 1.70 (1.27 to 2.28$)$ \\
\hline
\end{tabular}

${ }^{*}$ Control interventions: placebo, oral antidiabetic medication, or insulin.

†High doses: $20 \mu \mathrm{g} /$ day for exenatide; $1.8 \mathrm{mg} /$ day for liraglutide.

łLow doses: $10 \mu \mathrm{g} /$ day for exenatide; $1.2 \mathrm{mg} /$ day for liraglutide. 


\section{Figures}

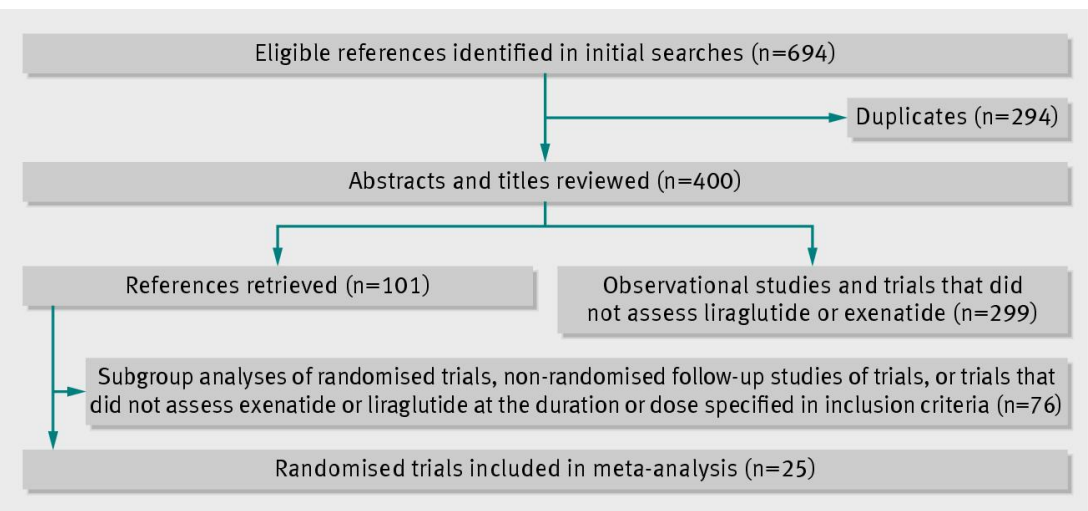

Fig 1 Flow chart for identification and selection of included randomised trials

\begin{tabular}{|c|c|c|c|c|c|c|c|c|}
\hline \multirow[b]{2}{*}{ Trial } & \multicolumn{2}{|c|}{ No of patients } & \multicolumn{2}{|c|}{$\begin{array}{c}\text { Mean change } \\
\text { (standard deviation) }\end{array}$} & & & \multirow[b]{2}{*}{$\begin{array}{l}\text { Weight } \\
\text { (\%) }\end{array}$} & \multirow[b]{2}{*}{$\begin{array}{c}\text { Weighted mean } \\
\text { difference }(95 \% \mathrm{Cl})\end{array}$} \\
\hline & $\begin{array}{l}\text { GLP-1R } \\
\text { gonist group }\end{array}$ & $\begin{array}{l}\text { Control } \\
\text { group }\end{array}$ & $\begin{array}{c}\text { GLP-1R } \\
\text { agonist group }\end{array}$ & $\begin{array}{l}\text { Control } \\
\text { group }\end{array}$ & \multicolumn{2}{|r|}{$\begin{array}{l}\text { Weighted mean } \\
\text { difference }(95 \% \mathrm{Cl})\end{array}$} & & \\
\hline Bergenstal 2010 & 160 & 166 & $-2.3(3.0)$ & $-0.8(0.3)$ & & $\Rightarrow$ & 4.98 & $-1.50(-1.97$ to -1.03$)$ \\
\hline Buse 2004 & 129 & 123 & $-1.6(3.4)$ & $-0.6(3.3)$ & & $\rightarrow-$ & 4.74 & $-1.00(-1.83$ to -0.17$)$ \\
\hline Kendall 2005 & 241 & 247 & $-1.6(3.1)$ & $-0.9(3.1)$ & & $\rightarrow$ & 4.93 & $-0.70(-1.26$ to -0.14$)$ \\
\hline Pratley 2010 & 221 & 219 & $-3.4(3.0)$ & $-1.0(1.8)$ & & - & 4.98 & $-2.42(-2.88$ to -1.96$)$ \\
\hline Moretto 2008 & 78 & 78 & $-3.1(2.7)$ & $-1.4(2.7)$ & & $\rightarrow-$ & 4.74 & $-1.70(-2.53$ to -0.87$)$ \\
\hline Nauck 2009 & 242 & 122 & $-2.8(0.2)$ & $-1.5(0.3)$ & & - & 5.09 & $-1.30(-1.36$ to -1.24$)$ \\
\hline Garber 2009 & 246 & 248 & $-2.5(7.8)$ & $1.0(7.9)$ & & $=$ & 4.21 & $-3.50(-4.89$ to -2.11$)$ \\
\hline Diamant 2010 & 233 & 223 & $-2.6(3.1)$ & $1.4(3.0)$ & $\rightarrow$ & - & 4.93 & $-4.00(-4.55$ to -3.45$)$ \\
\hline DeFronzo 2010 & 45 & 45 & $-2.8(3.4)$ & $1.5(3.4)$ & & & 4.21 & $-4.30(-5.69$ to -2.91$)$ \\
\hline Russell-Jones 2009 & 99230 & 114 & $-1.8(5.0)$ & $-0.4(4.1)$ & & $\rightarrow-$ & 4.59 & $-1.38(-2.38$ to -0.38$)$ \\
\hline Heine 2005 & 282 & 267 & $-2.3(3.9)$ & $1.8(4.0)$ & $\rightarrow$ & & 4.86 & $-4.10(-4.76$ to -3.44$)$ \\
\hline Astrup 2009 & 93 & 98 & $-7.2(0.5)$ & $-2.8(0.5)$ & - & & 5.08 & $-4.40(-4.54$ to -4.26$)$ \\
\hline Elkin 2010 & 20 & 20 & $-3.2(0.5)$ & $-1.6(0.9)$ & & $\rightarrow$ & 4.99 & $-1.60(-2.04$ to -1.16$)$ \\
\hline Davies 2009 & 118 & 117 & $-2.7(3.4)$ & $3.0(3.4)$ & $\rightarrow-$ & & 4.72 & $-5.71(-6.57$ to -4.85$)$ \\
\hline Rosenstock 2010 & 73 & 70 & $-5.1(0.5)$ & $-1.6(0.5)$ & & - & 5.08 & $-3.50(-3.66$ to -3.34$)$ \\
\hline Zinman 2009 & 178 & 177 & $-2.0(4.0)$ & $0.6(4.0)$ & & - & 4.74 & $-2.60(-3.43$ to -1.77$)$ \\
\hline Apovian 2010 & 96 & 98 & $-6.2(0.5)$ & $-4.0(0.5)$ & & . & 5.08 & $-2.19(-2.34$ to -2.04$)$ \\
\hline Bergenstal 2009 & 124 & 124 & $-1.9(3.8)$ & $4.1(5.4)$ & $\rightarrow-$ & & 4.44 & $-6.00(-7.16$ to -4.84$)$ \\
\hline Bunck 2009 & 36 & 33 & $-3.6(3.6)$ & $1.0(4.6)$ & $\longrightarrow$ & & 3.59 & $-4.60(-6.56$ to -2.64$)$ \\
\hline Marre 2009 & 234 & 114 & $-0.2(0.0)$ & $-0.1(0.6)$ & & 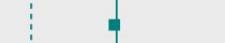 & 5.08 & $-0.10(-0.22$ to 0.02$)$ \\
\hline Nauck 2007 & 253 & 248 & $-2.5(3.2)$ & $2.9(3.0)$ & $\Rightarrow$ & & 4.94 & $-5.40(-5.94$ to -4.86$)$ \\
\hline \multirow[t]{2}{*}{ Overall; $P=0.00$} & & & & & & 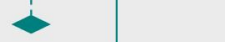 & 100.00 & $-2.90(-3.59$ to -2.22$)$ \\
\hline & & & & & .16 & 0 & 16 & \\
\hline
\end{tabular}

Fig 2 Meta-analysis of change in body weight $(\mathrm{kg})$ in included trials after at least 20 weeks of treatment, using random effects model 


\begin{tabular}{|c|c|c|c|c|c|c|c|}
\hline \multirow[b]{2}{*}{ Trial } & \multicolumn{2}{|c|}{ No of patients } & \multicolumn{2}{|c|}{$\begin{array}{c}\text { Mean change } \\
\text { (standard deviation) }\end{array}$} & \multirow[b]{2}{*}{$\begin{array}{l}\text { Weighted mean } \\
\text { difference }(95 \% \mathrm{Cl})\end{array}$} & \multirow[b]{2}{*}{$\begin{array}{l}\text { Weight } \\
\text { (\%) }\end{array}$} & \multirow[b]{2}{*}{$\begin{array}{c}\text { Weighted mean } \\
\text { difference }(95 \% \mathrm{Cl})\end{array}$} \\
\hline & $\begin{array}{c}\text { GLP-1R } \\
\text { agonist group }\end{array}$ & $\begin{array}{l}\text { Control } \\
\text { group }\end{array}$ & $\begin{array}{c}\text { GLP-1R } \\
\text { agonist group }\end{array}$ & $\begin{array}{l}\text { Control } \\
\text { up group }\end{array}$ & & & \\
\hline Astrup 2010 & 82 & 78 & $-6.9(1.3)$ & $-4.0(1.2)$ & $=$ & 10.59 & $-2.90(-3.29$ to -2.51$)$ \\
\hline Apovian 2010 & 96 & 98 & $-9.4(1.4)$ & $-2.0(1.4)$ & - & 10.59 & $-7.47(-7.86$ to -7.08$)$ \\
\hline Bergensthal 2010 & 160 & 166 & $-3.2(12.7)$ & $0.8(12.7)$ & & 8.72 & $-4.00(-6.76$ to -1.24$)$ \\
\hline Bunck 2009 & 36 & 33 & $-3.5(12.8)$ & $0.9(18.0)$ & & 4.09 & $-4.40(-11.83$ to -3.03$)$ \\
\hline Davies 2009 & 118 & 117 & $-2.9(13.0)$ & $0.7(13.0)$ & & 8.05 & $-3.60(-6.93$ to -0.27$)$ \\
\hline Moretto 2008 & 78 & 77 & $-4.3(13.3)-$ & $-0.08(12.3)$ & & 7.23 & $-4.22(-8.25$ to -0.19$)$ \\
\hline Garber 2009 & 217 & 212 & $-3.6(14.1)$ & $0.7(13.7)$ & & 8.86 & $-4.30(-6.93$ to -1.67$)$ \\
\hline Zinman 2009 & 178 & 177 & $-5.6(14.7)$ & $-1.1(16.0)$ & & 8.21 & $-4.50(-7.69$ to -1.31$)$ \\
\hline Kendall 2005 & 241 & 247 & $-2.0(15.0)$ & $1.1(14.7)$ & & 8.85 & $-3.10(-5.74$ to -0.46$)$ \\
\hline Buse 2004 & 129 & 123 & $0.8(15.7)$ & $-1.6(14.3)$ & & 7.61 & $-2.40(-1.30$ to 6.10$)$ \\
\hline Diamant 2010 & 233 & 223 & $-3.0(16.6)$ & $-0.6(14.9)$ & & 8.56 & $-2.40(-5.29$ to 0.49$)$ \\
\hline Heine 2005 & 282 & 267 & $-4.1(17.8)$ & $-0.6(16.0)$ & - & 8.63 & $-3.50(-6.33$ to -0.67$)$ \\
\hline \multirow[t]{2}{*}{ Overall; $P=0.00$} & & & & & & 100.00 & $-3.57(-5.49$ to -1.66$)$ \\
\hline & & & & & 0 & 1.8 & \\
\hline
\end{tabular}

Fig 3 Meta-analysis of change in systolic blood pressure $(\mathrm{mm} \mathrm{Hg})$ in included trials after at least 20 weeks of treatment, using random effects model

\begin{tabular}{|c|c|c|c|c|c|c|c|c|}
\hline \multirow[b]{2}{*}{ Trial } & \multicolumn{2}{|c|}{ No of patients } & \multicolumn{2}{|c|}{$\begin{array}{c}\text { Mean change } \\
\text { (standard deviation) }\end{array}$} & \multirow{2}{*}{\multicolumn{2}{|c|}{$\begin{array}{c}\text { Weighted mean } \\
\text { difference }(95 \% \mathrm{Cl})\end{array}$}} & \multirow[b]{2}{*}{$\begin{array}{l}\text { Weight } \\
(\%)\end{array}$} & \multirow[b]{2}{*}{$\begin{array}{l}\text { Weighted mean } \\
\text { difference }(95 \% \mathrm{Cl})\end{array}$} \\
\hline & $\begin{array}{l}\text { GLP-1R } \\
\text { Igonist group }\end{array}$ & $\begin{array}{l}\text { Control } \\
\text { group }\end{array}$ & $\begin{array}{c}\text { GLP-1R } \\
\text { agonist group }\end{array}$ & $\begin{array}{l}\text { Control } \\
\text { group }\end{array}$ & & & & \\
\hline Astrup 2010 & 82 & 78 & $-2.9(0.8)$ & $-1.1(0.8)$ & $\mathbf{E}_{\mathrm{i}}$ & & 19.34 & $-1.80(-2.05$ to -1.55$)$ \\
\hline Moretto 2008 & 78 & 77 & $-2.9(8.4)$ & $0.1(8.3)$ & & & 4.60 & $-3.00(-5.63$ to -0.37$)$ \\
\hline Apovian 2010 & 96 & 98 & $-2.2(1.0)$ & $0.5(1.0)$ & $=$ & & 19.20 & $-2.69(-2.97$ to -2.41$)$ \\
\hline Zinman 2009 & 178 & 177 & $-1.9(9.3)$ & $-0.8(9.3)$ & & - & 7.08 & $-1.10(-3.04$ to 0.84$)$ \\
\hline Bergensthal 2010 & 160 & 166 & $-1.6(7.5)$ & $-0.2(8.1)$ & & & 8.36 & $-1.40(-3.09$ to 0.29$)$ \\
\hline Heine 2005 & 282 & 267 & $-1.2(10.3)$ & $-0.8(9.8)$ & & & 8.43 & $-0.40(-2.08$ to 1.28$)$ \\
\hline Diamant 2010 & 233 & 223 & $-1.2(10.1)$ & $-0.7(8.7)$ & & & 8.17 & $-0.50(-2.23$ to 1.23$)$ \\
\hline Davies 2009 & 118 & 117 & $-0.5(7.6)$ & $0.9(7.6)$ & & - & 7.08 & $-1.40(-3.34$ to 0.54$)$ \\
\hline Buse 2004 & 129 & 123 & $-0.5(9.4)$ & $-0.6(8.6)$ & & & 5.89 & $-0.13(-2.09$ to 2.35$)$ \\
\hline Kendall 2005 & 241 & 247 & $-0.4(8.9)$ & $-0.9(9.0)$ & & -1 & 8.99 & $-0.50(-1.09$ to 2.09$)$ \\
\hline Bunck 2009 & 36 & 33 & $-0.3(6.2)$ & $1.7(8.4)$ & $-!$ & & 2.87 & $-2.00(-5.51$ to 1.51$)$ \\
\hline \multirow[t]{2}{*}{ Overall; $P=0.00$} & & & & & $<$ & & 100.00 & $-1.38(-2.02$ to -0.73$)$ \\
\hline & & & & & & 0 & & \\
\hline
\end{tabular}

Fig 4 Meta-analysis of change in diastolic blood pressure $(\mathrm{mm} \mathrm{Hg})$ in included trials after at least 20 weeks of treatment, using random effects model

\begin{tabular}{|c|c|c|c|c|c|c|c|}
\hline \multirow[b]{2}{*}{ Trial } & \multicolumn{2}{|c|}{ No of patients } & \multicolumn{2}{|c|}{$\begin{array}{c}\text { Mean change } \\
\text { (standard deviation) }\end{array}$} & \multirow[b]{2}{*}{$\begin{array}{c}\text { Weighted mean } \\
\text { difference }(95 \% \mathrm{Cl})\end{array}$} & \multirow[b]{2}{*}{$\begin{array}{l}\text { Weight } \\
\text { (\%) }\end{array}$} & \multirow[b]{2}{*}{$\begin{array}{l}\text { Weighted mean } \\
\text { difference }(95 \% \mathrm{Cl})\end{array}$} \\
\hline & $\begin{array}{c}\text { GLP-1R } \\
\text { agonist group }\end{array}$ & $\begin{array}{l}\text { Control } \\
\text { group }\end{array}$ & $\begin{array}{c}\text { GLP-1R } \\
\text { agonist group }\end{array}$ & $\begin{array}{c}\text { Control } \\
\text { group }\end{array}$ & & & \\
\hline Heine 2005 & 282 & 267 & $-0.1(0.7)$ & $-0.0(0.9)$ & $\rightarrow$ & 18.57 & $-0.09(-0.23$ to 0.05$)$ \\
\hline Bergensthal 2010 & 160 & 166 & $0.1(0.7)$ & $0.0(0.8)$ & & 12.30 & $0.06(-0.11$ to 0.23$)$ \\
\hline Buse 2009 & 129 & 123 & $-0.1(0.7)$ & $0.1(0.7)$ & $\rightarrow-$ & 11.22 & $-0.18(-0.35$ to -0.01$)$ \\
\hline Davies 2009 & 118 & 117 & $-0.4(0.8)$ & $-0.2(0.8)$ & $\rightarrow$ & 9.04 & $-0.15(-0.34$ to 0.04$)$ \\
\hline Kendall 2005 & 241 & 247 & $0.0(0.8)$ & $0.1(0.9)$ & $\longrightarrow$ & 15.64 & $-0.07(-0.22$ to 0.08$)$ \\
\hline Diamant 2010 & 233 & 223 & $-0.1(0.8)$ & $-0.0(0.7)$ & $\longrightarrow$ & 17.92 & $-0.08(-0.22$ to 0.06$)$ \\
\hline Bunck 2009 & 36 & 33 & $-0.3(0.8)$ & $-0.2(0.6)$ & & 3.09 & $-0.10(-0.43$ to 0.23$)$ \\
\hline DeFronzo 2010 & 45 & 45 & $0.13(0.8)$ & $0.4(0.8)$ & & 3.08 & $-0.31(-0.64$ to 0.02$)$ \\
\hline Moretto 2008 & 78 & 77 & $-0.1(0.9)$ & $0.2(0.9)$ & i & 4.24 & $-0.30(-0.58$ to -0.02$)$ \\
\hline Zinman 2009 & 178 & 177 & $-0.2(1.2)$ & $-0.0(1.3)$ & \begin{tabular}{c:ccc}
1 \\
\hdashline
\end{tabular} & 4.90 & $-0.18(-0.44$ to 0.08$)$ \\
\hline \multirow[t]{2}{*}{ Overall; $P=0.468$} & & & & & $\rightarrow$ & 100.00 & $-0.10(-0.16$ to -0.04$)$ \\
\hline & & & & & 0 & & \\
\hline
\end{tabular}

Fig 5 Meta-analysis of change in concentration of total cholesterol $(\mathrm{mmol} / \mathrm{L})$ in included trials after at least 20 weeks of treatment, using random effects model 


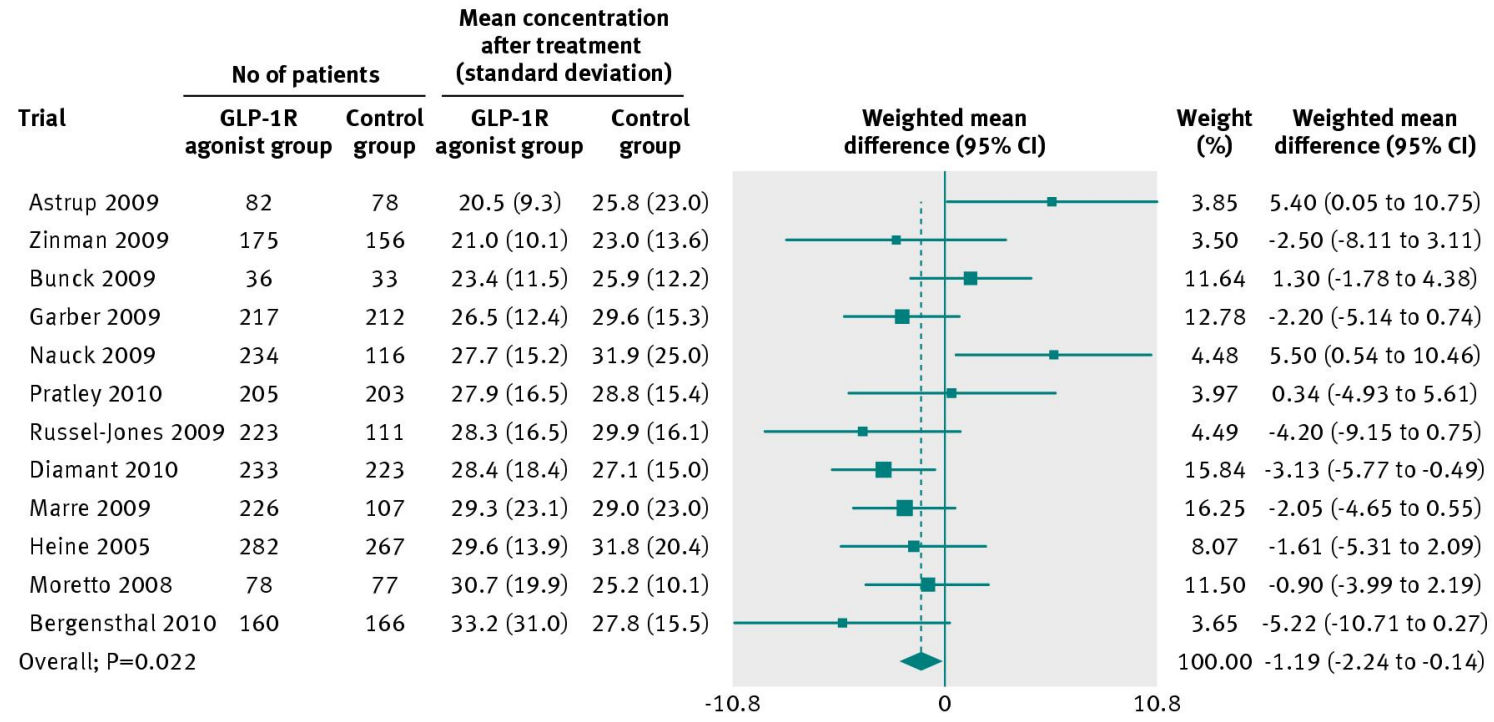

Fig 6 Meta-analysis of change in concentration of alanine aminotransferase (U/L) in included trials after at least 20 weeks of treatment, using fixed effects model

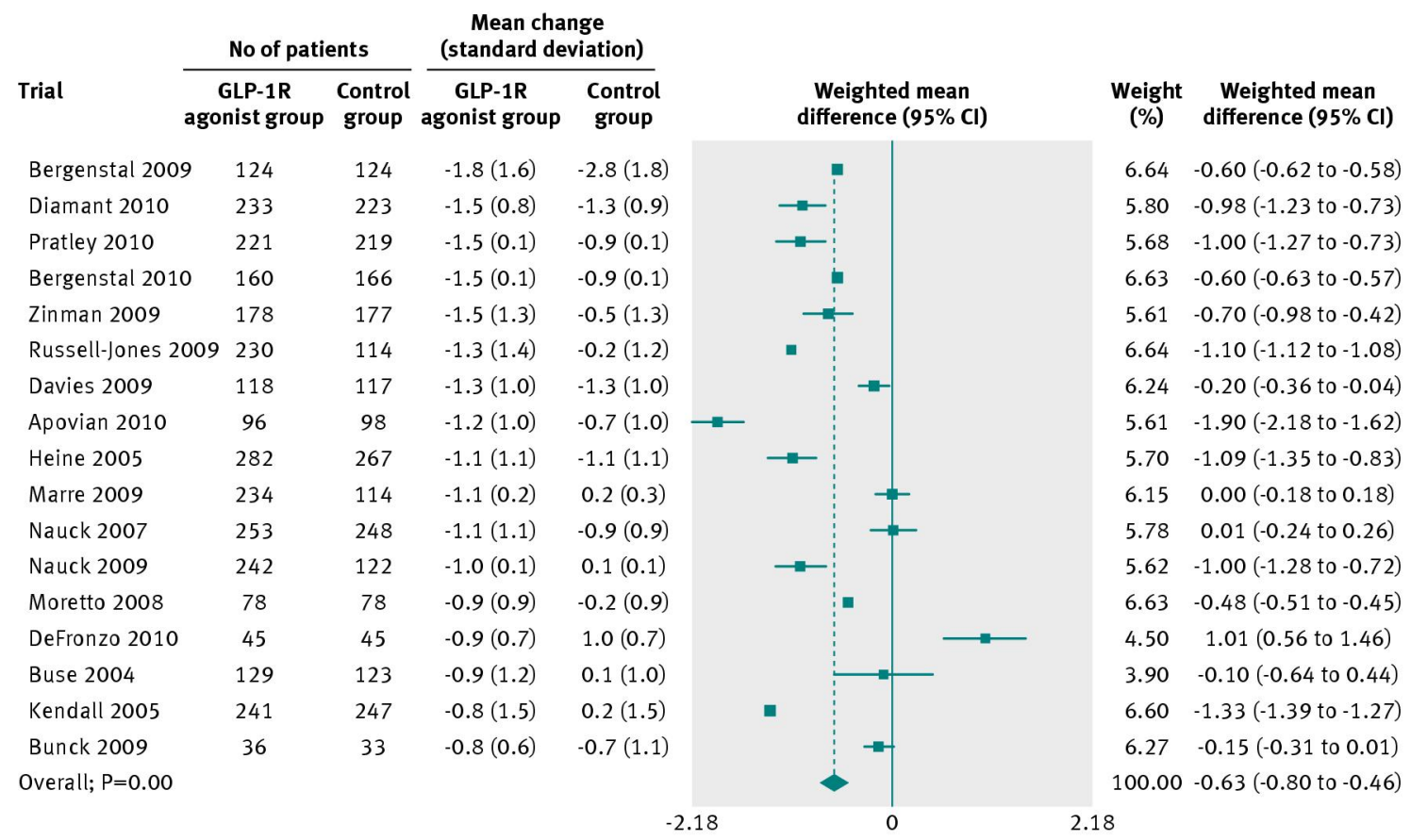

Fig 7 Meta-analysis of reduction in $\mathrm{HbA}_{1 \mathrm{c}}$ percentage in included trials after at least 20 weeks of treatment, using random effects model 